\title{
ANDERNACHT, Dietrich, Regesten zur Geschichte der Juden in der Reichsstadt Frankfurt am Main von
} 1401-1519

Pierre Monnet

\section{(2) OpenEdition \\ Journals}

Édition électronique

URL : http://journals.openedition.org/ifha/1437

DOI : 10.4000/ifha. 1437

ISSN : 2198-8943

Éditeur

IFRA - Institut franco-allemand (sciences historiques et sociales)

Référence électronique

Pierre Monnet, «ANDERNACHT, Dietrich, Regesten zur Geschichte der Juden in der Reichsstadt Frankfurt am Main von 1401-1519», Revue de l'IFHA [En ligne], Date de recension, mis en ligne le 01 janvier 1998, consulté le 22 septembre 2020. URL : http://journals.openedition.org/ifha/1437 ; DOI : https://doi.org/ 10.4000/ifha. 1437

Ce document a été généré automatiquement le 22 septembre 2020.

(CIFHA 


\title{
ANDERNACHT, Dietrich, Regesten zur Geschichte der Juden in der Reichsstadt Frankfurt am Main von 1401-1519
}

\author{
Pierre Monnet
}

1 Ces trois volumes de sources, que D.A. put encore éditer peu avant sa mort, rassemblent 4262 documents publiés ou restitués afin de mieux servir et comprendre l'histoire des Juifs de Francfort entre 1401 et 1519. Un index des lieux et des personnes doit encore venir compléter cette publication d'une richesse exceptionnelle et qui rendra un immense service à tous les historiens des villes et de la société à la fin du Moyen Age. L'auteur, qui a travaillé depuis 30 ans à cet ouvrage, regroupe ici les lettres publiques, correspondances privées, arrêts du Conseil, rapports d'ambassades, jugements, reconnaissances de dettes, prêts, rentes, quittances d'impôt... permettant d'éclairer tous les aspects de la vie d'une communauté qui connut, à Francfort, un sort très mouvementé.

2 De très nombreux documents sont extraits des livres des bourgmestres (Bürgermeisterbücher) dont la plupart des rapports annuels ont disparu dans le grand incendie des archives de la ville en 1944. Mais la richesse, et quelquefois les paradoxes ou hésitations des décisions encore conservées, disent assez la valeur de cette série devenue si lacunaire. La disposition chronologique de cette publication permet de saisir les grands traits d'une évolution riche de contrastes entre 1401 et 1519. Avant même le XVe s., la communauté juive de Francfort, à la fois corsetée et protégée par son statut de "serfs de la chambre impériale«, avait réussi, en dépit du pogrom de 1241, à développer une vie économique, culturelle et religieuse active dans un quartier situé aux bords du Main entre l'ancien palais royal (Pfalz) et la collégiale (Bartholomäusstift), soit un espace qui, à l'origine, avait vraisemblablement relevé du roi. Bourgeois de la ville et ne ressortant que des tribunaux urbains, les Juifs avaient leur propre organisation assurée par trois représentants. Après les massacres perpétrés dans d'autres villes rhénanes, le "pogrom de la peste« de 1349 à Francfort réduit presque à 
néant l'existence d'une communauté riche et active, dévastation dans laquelle le Conseil semble avoir joué un rôle pour le moins ambigu.

3 En 1360, puisque le quartier naguère occupé avait été entre temps colonisé par la collégiale Saint-Barthélemy, par le cimetière urbain, mais aussi par l'archevêque de Mayence et les Mendiants, un nouvel espace fut attribué aux quelques familles demeurées en ville. En 1372, Charles IV abandonna pour 6000 florins au Conseil les derniers droits du roi sur les Juifs de la ville. C'est donc sous ce régime nouveau d'une entière dépendance vis-à-vis de l'autorité urbaine que les sources ici rassemblées considèrent l'évolution d'un groupe dont le nombre ne s'est jamais remis des massacres de 1349: à peine 20 foyers vers 1410 , seulement quatre en 1416 et six en 1431 . Les documents permettent de suivre, année après année, la lente dégradation du statut des Juifs et les restrictions répétées émises principalement par le Conseil: la fermeture du quartier en un véritable ghetto entre 1432 et 1438 ou les interdits vestimentaires et professionnels pour n'en citer que quelques exemples.

$4 \mathrm{Au}$ terme de cette politique dont les sources réunies prouvent la continuité et, en partie, la cohérence, surgit en 1458 la construction annoncée d'un ghetto organisé pour une centaine de personnes: une longue rue sombre, la Judengasse, réunissant de manière fonctionnelle la synagogue, les bains, les points d'eau et les habitations. C'est donc dans l'exclusion planifiée que la politique d'aménagement urbain conçue au XVe s. s'est exprimée de la manière la plus achevée!

5 Mais jusqu'à présent, ni l'exercice du culte ni l'activité si poussée de l'enseignement n'avaient été touchés. Or, et c'est là un des grands intérêts du recueil qui choisit d'aller jusqu'en 1519, le début du XVIe s. voit l'ensemble des livres de prière et d'école confisqués pour quelques années, à l'initiative d'un juif converti, un certain Pfefferkorn. La pré-Réforme s'est donc bien signalée, à Francfort comme ailleurs, par une accentuation de l'exclusion et de la discrimination à l'égard des Juifs à mesure que les conflits de toute la société se cristallisaient autour des débats religieux. Dans les années 1515-1520, seul l'empereur, par un paradoxe qui n'est qu'apparent, devenait le dernier garant d'un statut minimal qui évita aux Juifs une expulsion générale que réclamaient à Francfort autant l'archevêque de Mayence que les écrits de Luther.

Ce recueil retrace donc une évolution saisie sur un temps long, qui mène de la période d'une certaine »citoyenneté« des Juifs à celle du contrat sans cesse rogné et amoindri par des autorités urbaines dont les décisions sont de plus en plus envahies par des enjeux religieux à l'approche des dernières décennies précédant la Réforme. Entre cohabitation et partage des droits d'une part et »contrat « communautaire de l'autre, le statut des Juifs, dans une ville de la fin du Moyen Age, ici Francfort, n'est donc pas sans rappeler les thèmes et les termes d'un débat, cette fois plus contemporain, portant sur la place et la coexistence des communautés dans nos sociétés citadines.

Pierre MONNET 